\title{
Observations on the behaviour of a piled-raft foundation on London Clay
}

J. A. HOOPER

Mr E. N. Bromhead, Kingston Polytechnic

The Paper adds greatly to the understanding of the behaviour of such complex foundations. However, the Author's analysis is only a class B prediction. Has this method been used on projects to provide a class A prediction of settlements?

69. Close inspection of the chosen finite element mesh reveals points not covered in the Paper. Does the program allow a variation of soil properties across each element? The mesh appears excessively fine in view of the neglect of stress values distant from the raft, and many elements have poor aspect ratios. Would the Author comment on permissible distortions for this element?

70. The choice of the position and type of boundaries (i.e. smooth, rough, rigid or elastically restrained) at the sides and base of the model are of paramount importance to the settlement values. Indeed, the choice of boundaries may have as much influence on the computed settlements as may the choice of other factors normally considered of greater significance, such as the chosen value of Poisson's ratio.

71. In this context the use of an undrained Poisson's ratio of 0.47 is noted. Since the chosen element is capable of simulating much less compressible behaviour if a minimum integrating order is used would the Author comment on the choice of the low value? (In such a case one may not always trust nodal stresses, but that is rarely a great loss.)

72. In $\S 27$ it is suggested that shear tractions at the soil-raft interface are negligible. It is certainly obvious that in the model with its concentric cylindrical reinforcements (piles) shear strains are prevented, but it is equally as evident that this is not so in the prototype. The results of reference 10 are important in this context.

73. The Author's final comments on the rate of settlement are also important. Does his settlement analysis take into account radial drainage? If not, it is hardly surprising that calculated settlement rates are inaccurate (even taking into account factors such as the true consolidation behaviour of the London Clay). It is probable that radial drainage has a greater influence with this geometric configuration than the influence of preferential horizontal drainage paths. Would a coupled (i.e. Biot) type of consolidation theory not provide a more elegant solution to this problem and would it yield the same undrained and drained settlements or would load transfers during the consolidation process lead to a different final settlement picture?

Mr D. K. Doran, George Wimpey \& Co. Ltd

Could the Author give details of any estimates that were made of the likely settlement of the block using a raft without piles?

Paper published: Proc. Instn Civ. Engrs, Part 2, 1973, 55, Dec., 855-877. 
75. As the result of observations made, can any comment be made on the percentage and distribution of reinforcement in the slab at $9.4 \mathrm{~m}$ OD?

\section{Mr E. H. Steger, Pell Frischmann \& Partners}

During 1961, while in Wimpey's laboratories, I was in charge of the site investigation and detailed foundation design and settlement analyses for Ove Arup \& Partners. Relatively few structural details were known at that time. Further, in 1961 knowledge of the behaviour of under-reamed piles was based on conjecture, extrapolation, theory, engineering judgement, intelligent guessing and wishful thinking. I am not sure that much of this does not still apply.

77. Computer programs for settlement analyses had not then been developed and consequently the well-established Skempton-Bjerrum method ${ }^{20}$ was used, employing some changes which did not seem inappropriate, such as taking a 1:6 spread from pile head rather than an equivalent raft further down. Depth and rigidity corrections were also applied.

78. It is interesting to apply the actual foundation design and net loadings given in the Paper to the graphs drawn up in 1961. The elastic settlements predicted at that time were about $20 \mathrm{~mm}$ for the centre and $7 \mathrm{~mm}$ for the corner of the raft, i.e. they were within a few millimetres of both computer calculated and of measured settlements.

79. For a National Westminster Bank in London the most elaborate computer analyses gave settlement estimates of much the same order of magnitude as those arrived at by a sophisticated hand method. Since either case can only show an order of magnitude, in view of the variability of soil properties, unpredictability of soilstructure interaction and lack of knowledge of the behaviour of the structure, I am not convinced that it is useful to employ computers for such an exercise. It certainly is not economical.

\section{Professor Chin Fung Kee, Jurutera Konsultant, Kuala Lumpur}

A piled raft is a complex foundation and its analysis requires the knowledge of parameters which are not easily ascertained or available. Consequently, field measurements and observations on the behaviour of the structure are necessary to determine the validity of the assumptions and the principles embodied in the analysis.

81. Two important design considerations require early confirmation with the field observations: an estimate of the ultimate capacity of the piled raft and an estimate of its final settlement.

82. It has been shown ${ }^{21-23}$ that the load/settlement relationship of a foundation is hyperbolic and that a plot of $\Delta / P$ against an abscissa of $\Delta$, where $P$ is the load corresponding to a settlement $\Delta$, is linear. The inverse slope of this line, therefore, gives the ultimate value of $P$. This finding enables the ultimate load of a foundation to be obtained without the necessity of having to carry out the load test until the ultimate value is reached. In the case of a raft foundation such as that described in the Paper, an actual load test need not be carried out. In any case the load required would be so large as to make the conduct of a normal load test on the raft foundation as a whole to be impractical and expensive. In such a case $P$ is the building weight and the settlement $\Delta$ corresponding to a building weight $P$ is measured as the construction of the building progresses. Where there is heave, the magnitudes of $\Delta$ and $P$ are those taken from the end of heave.

83. The final settlement, which is reached only after a very long time, can be predicted at an early date from field observations such as those made by the Author. Load is a function of settlement and here the settlement $\Delta$ at a time $t$ is measured from the time when the building is completed and commissioned, when it can reasonably be said that the foundation begins to bear a fairly constant load. Tan ${ }^{24}$ and $C^{2}$ hin $^{25}$ have shown that if $t / \Delta$ is plotted against $t$ the inverse slope gives an estimation of the 
Fig. 16

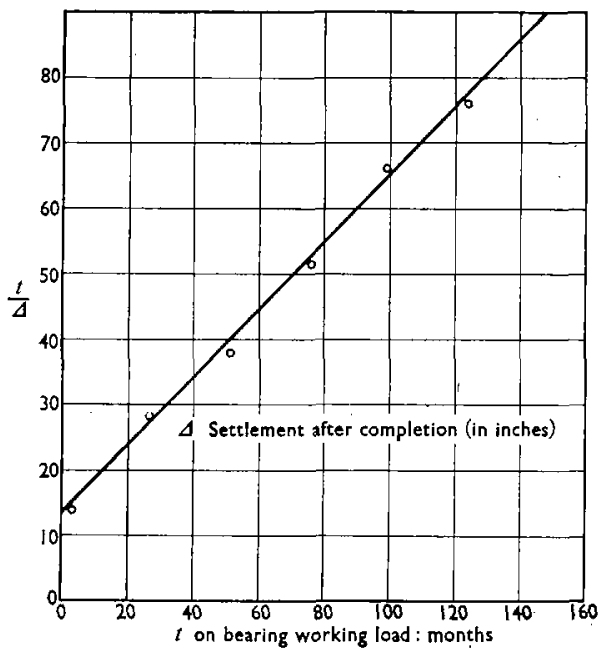

final settlement, e.g. Fig. 16, which is drawn from the results of Skempton et al. ${ }^{26}$ This foundation is $27 \mathrm{ft}$ wide and $117 \mathrm{ft}$ long resting on blue London Clay. The relationship between $t / \Delta$ and $t$ is linear and the inverse slope gives a value of about 2 in. as the settlement this foundation would further attain after it begins to bear its full working load.

\section{Dr Hooper}

In reply to $\mathrm{Mr}$ Bromhead, the type of analysis referred to in the Paper has so far been restricted to class $\mathbf{B}$ and class $\mathbf{C}$ predictions. ${ }^{27}$ Further work is required before the method can be used for class A predictions, although its application to a number of future projects is currently under consideration.

85. The computer program used in the analysis allowed a linear variation of Young's modulus with depth across each soil element, thereby avoiding a stepwise simulation of equations (1) and (3). The finite element mesh itself can hardly be considered as excessively fine in view of the complex shape of the foundation; indeed, efforts were made to minimize the total number of elements by representing each pile annulus by a single column of elements and by adopting a spider's web form of mesh layout. Consequently the aspect ratios of some of the pile elements are rather high, but not high enough to be of concern. However, a proper assessment of the approximations implicit in the annuli-type of representation of the pile group must await a fully three-dimensional solution to the problem.

86. The boundaries to the finite element model are sufficiently distant from the foundation as to be relatively unimportant, although the computed settlements for the undrained case are increased slightly if the right-hand side boundary is completely unrestrained. Other work has indicated that an unrestrained boundary may have been a rather better representation of in situ conditions than the roller-type boundary used in the piled-raft analyses, although the effect of such a change on the undrained displacements plotted in Fig. 13 would be barely discernible.

87. A Poisson's ratio of 0.47 was used in the undrained analyses to avoid the computational difficulties usually encountered when values close to 0.5 are used. However, subsequent work has shown that, provided a reduced integration procedure 
is adopted and that stresses are output at the Gauss sampling points, values of Poisson's ratio at least as high as 0.499 can be used with confidence. For the present problem, the results obtained from an analysis with $v=0.499$ would be similar to those reported in the Paper for the undrained case.

88. A detailed analysis of a preliminary test problem (i.e. a circular raft on an elastic layer) showed that the effects of shear traction on the raft base are likely to be small, provided that the raft is at least moderately stiff. The piled-raft foundation falls into this category, and the additional lateral restraint provided by the piles will reduce the shear traction effects still further.

89. The comments in the Paper on rate of settlement were made on the basis of approximate calculations that accounted for radial as well as vertical drainage, which led to the assertion that laboratory $c_{\mathrm{v}}$ values appear to bear little resemblance to in situ values. The finite element analysis gives only upper and lower bounds for settlement and does not solve the time-dependent consolidation equations. However, a more recent analysis ${ }^{28}$ carried out in terms of effective stress parameters gives the same final settlements as would be expected from a rigorous Biot-type analysis, and this finite element model could be adapted to include the time variable.

90. In answer to Mr Doran, the volumetric percentage of steel in the raft is approximately $0 \cdot 8$. The distribution of steel is similar in each direction (i.e. parallel to the orthogonal axes of the superstructure) and the volumetric percentages of top and bottom steel are 0.2 and 0.6 respectively.

91. There are no records of estimates having been made (before construction) of the settlement of the raft without piles. However, the finite element analyses reported in the Paper have been extended to include the effect on raft settlement of progressively shortening the piles. The results are shown in Fig. 17 and relate to settlements under the full building weight for undrained $\left(\nu_{u}=0.47\right)$ and fully drained $\left(\nu^{\prime}=0 \cdot 10\right)$ conditions. All piles within the group were shortened equally at each step and the under-reamed bases were omitted after the first reduction in length. With short piles, the initial heave of the excavation would be rather greater than that assumed in the analysis, but the effect on total final settlements would be small.

92. Referring to Fig. 17, the effect of removing the piles is to increase the computed settlement at the raft centre by a factor of 1.8 (i.e. from 14.9 to $27.0 \mathrm{~mm}$ ) for the undrained case and by a factor of 2.5 (i.e. from 19.7 to $48.4 \mathrm{~mm}$ ) for the drained case. The maximum differential settlement increases by a factor of 1.6 (i.e. from 3.7 to $6.0 \mathrm{~mm}$ ) for both undrained and drained cases. In this connexion, a preliminary study ${ }^{a 9}$ of measured settlements of other tower block structures in London has indicated that, although piles reduce overall settlements, the stiffening effect of the superstructure is such that differential settlements will be approximately the same irrespective of whether or not the foundation is piled.

93. As it is the consolidation component of the total settlement that is the most likely potential cause of damage to services and architectural finishes, the ratio of the maximum undrained settlement of the raft $\rho_{u}$ to the maximum total (drained) settlement $\rho_{\mathrm{t}}$ is of interest. In Fig. 17, $\rho_{\mathrm{u}} / \rho_{\mathrm{t}}=0.76$ for the piled-raft foundation (i.e. with full length piles, $24.9 \mathrm{~m}$ long); with the piles completely removed, this ratio reduces to 0.56. However, for each type of foundation the change from the undrained to the drained condition has little effect on differential settlements $\Delta \rho$, i.e. in each case the computed values of $\Delta \rho_{\mathrm{u}} / \Delta \rho_{\mathrm{t}}$ are within $10 \%$ of unity.

94. It is also of interest to compare these values of $\rho_{\mathrm{u}} / \rho_{\mathrm{t}}$ with those for the case where the soil modulus is constant with depth. If an axisymmetric load is applied directly to the surface of a thick homogeneous elastic layer, for example, it follows from equation (2) that $\rho_{\mathrm{u}} / \rho_{\mathrm{t}}=\left(1-\nu_{\mathrm{u}}\right) /\left(1-\nu^{\prime}\right)=0.58$; in the present problem, the value of this ratio increases to approximately 0.63 because of the depth of the loaded surface below original ground level. Separate finite element analyses for the case of the piled raft embedded in a homogeneous stratum have shown that $\rho_{\mathrm{u}} / \rho_{\mathrm{t}}=0.72$, with $\Delta \rho_{\mathrm{u}} / \Delta \rho_{\mathrm{t}}$ close to unity as before. Hence for both the plain raft and piled-raft 


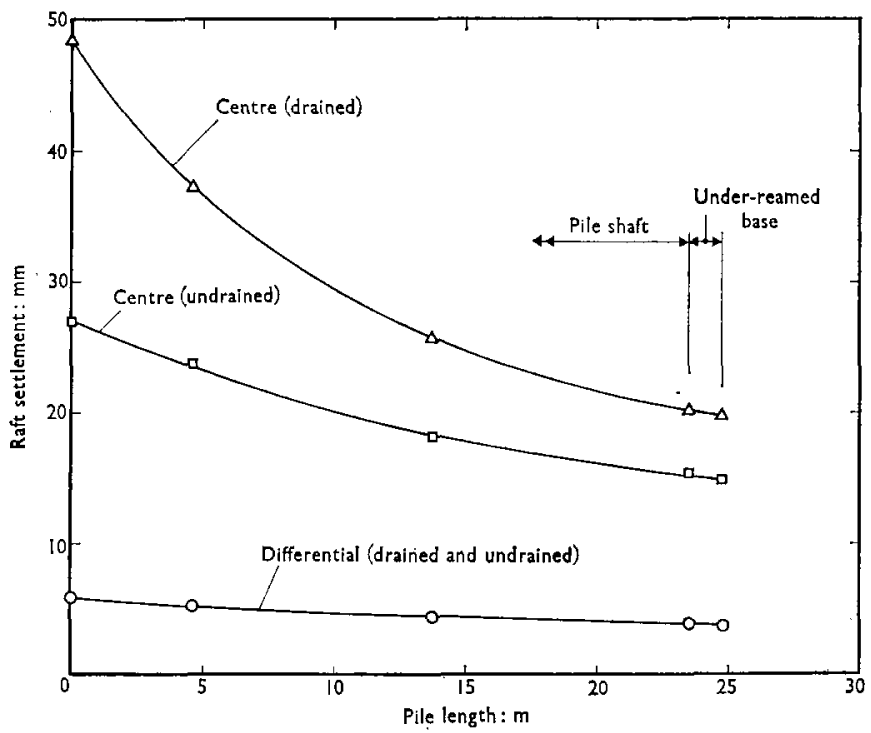

Fig. 17. Effect of reduction in pile length on raft settlement

foundations the values of $\rho_{u} / \rho_{t}$ do not differ appreciably from the corresponding values obtained on the basis of the non-homogeneous clay layer defined by equations (1) and (3). Further, if the $E$ value of the homogeneous layer is taken as the average $E$ value down the length of the piles (calculated from equations (1) and (3)) then the maximum total settlements (undrained and drained) are overestimated by only $25 \%$, and the maximum differential settlements underestimated by the same amount.

95. It is evident from Fig. 17 that the contribution of the lower half of the pile group in reducing settlements is comparatively small. In particular, the underreamed pile bases appear to have an almost negligible effect on the magnitude of foundation settlements. This in turn raises the question of how piled rafts are designed. The conventional design method is distinctly irrational in that the sizes of piles to be installed for the sole purpose of reducing raft settlements are determined on the basis of the ultimate load carrying capacity of a single pile, even when the bearing capacity of the foundation without piles is adequate in the first place. Clearly a design method based on the settlement characteristics of a pile group would lead to more reasonable estimates of pile length. Work on this aspect is currently in progress.

96. The site investigation report prepared by Mr Steger includes estimates of settlement based on a pile length of $33.5 \mathrm{~m}$ and a foundation plan area of $465 \mathrm{~m}^{2}$ with a correction applied to allow for the rigidity of the structure. Using the value of net applied loading $\left(196 \mathrm{kN} / \mathrm{m}^{2}\right)$ given in the Paper, Mr Steger's estimates for the final settlement (elastic plus consolidation) become $36 \mathrm{~mm}$ for the raft centre and 24 $\mathrm{mm}$ for the differential settlement. Likewise the estimated settlement at the raft centre after 50 years becomes $26 \mathrm{~mm}$, with a differential settlement of $18 \mathrm{~mm}$. The corresponding measured settlements six years after the start of construction, when primary consolidation appeared to be almost complete, were $21 \mathrm{~mm}$ (centre) and $6 \mathrm{~mm}$ (differential).

97. Calculations of the type referred to by Mr Steger are useful at the early design stage of a building, but shed little light on the likely structural behaviour of a piled- 
raft foundation. The conventional procedure yields virtually no information on, say, the load distribution within the pile group, the contact pressures on the base of the raft or the influence of the structural rigidity of the superstructure on differential settlements. Further, it does not provide a means by which piled rafts may be designed on a rational basis; indeed, it helps perpetuate a system that often gives rise to excessively long piles and that also leads to the construction of costly under-reamed pile bases, which in most cases serve little useful purpose.

98. In contrast, the type of analysis described in the Paper enables the relative importance of parameters such as soil modulus and pile length to be realistically assessed, and goes a long way towards establishing the framework necessary to improve the existing methods of designing piled-raft foundations. Modern computer technology has now developed to the extent that finite element analyses can be carried out at surprisingly low cost and, coupled with a good measure of engineering judgement, can often provide the key to the understanding of many complex and otherwise intractable problems.

99. Mr Chin deals with the inverse slope method of predicting the ultimate bearing capacity and final settlement of foundations. With regard to the former, the factor of safety against instability of foundations on London Clay is usually sufficiently high to warrant no further attention after the design stage. However, confirmation of settlement predictions is frequently required and the inverse slope method appears to have merit in certain cases, specifically where the construction time is short and where the value of $\rho_{\mathbf{u}} / \rho_{\mathbf{t}}$ is comparatively low, e.g. pad footings or plain raft foundations.

100. However, in the case of piled rafts the value of $\rho_{\mathrm{u}} / \rho_{\mathrm{t}}$ is relatively high, which, when coupled with a lengthy construction period, implies that the settlements occurring after construction will be a small proportion of the total. For the foundation described in the Paper the inverse slope method of settlement prediction does not seem to be applicable.

\section{References}

20. Skempton A. W. and Bjerrum L. A contribution to the settlement analysis of foundations on clay. Géotechnique, 1957, 7, Dec., 168-178.

21. Chin Fung KeE. Estimation of the ultimate load of piles from tests not carried to failure. Proc. 2nd S.E. Asian Conf. Soil Engng, Singapore, 1970, 81-90.

22. ChIn Fung KEe. The inverse slope as a prediction of ultimate bearing capacity of piles. Proc. 3rd S.E. Asian Conf. Soil Engng, Hong Kong, 1972. In press.

23. Chin Fung Kee and Vail A. J. Behaviour of piles in alluvium. Proc. 8th Int. Conf. Soil Mech., Moscow, 1973, 2.1, 47-52.

24. TAN Swan Beng. An empirical method for estimating secondary and total settlement. Proc. 4th Asian Reg. Conf. Soil Mech., Bangkok, 1971, 2, 147-151.

25. CHIN Fung KeE. Estimating the final total settlement-A theoretical analysis. Proc. 4th Asian Reg. Conf. Soil Mech., Bangkok, 1971, 2, 156-157.

26. SKempton A. W. et al. Settlement analyses of six structures in Chicago and London. Proc. Instn Civ. Engrs, 1955, 4, Part 1, July, 525-544.

27. Lambe T. W. Predictions in soil engineering. Géotechnique, 1973, 23, June, 151-201.

28. Naylor D. J. and Hooper J. A. An effective stress finite element analysis to predict the short-and long-term behaviour of a piled-raft foundation on London Clay. Proceedings of symposium on settlement of structures, Cambridge, 1974, 394-402.

29. Hooper J. A. and Beckmann P. A review of settlements observed on nine buildings in London. Ove Arup and Partners Interim Report 4568 to Building Research Establishment, 1973. 